\title{
Reduction of intra-operative blood loss by temporary control of external carotid artery in advanced head and neck malignancies
}

\author{
Hosam Abd El-Kader El-Fol, ${ }^{a}$ MD; Mamdouh S Ahmed, $b$ DDS
}

a) Department of Surgical Oncology, Menofia University, Menofia, Egypt. b) Department of Oral \& Maxillofacial Surgery, Faculty of Oral \& Dental Medicine, Cairo University, Cairo, Egypt.

\begin{abstract}
Objective: The study introduces a simple vascular control procedure to minimize intraoperative blood loss during resection of advanced head and neck malignancies through clamping to the external carotid artery (ECA).

Patients and methods: This prospective study included 20 patients with different operable head and neck cancer randomized to perform vascular clamping of ECA during neck dissection before tumor resection (group $A, n=11$ ) or classical neck dissection and resection of the tumors without vascular control (group $B, n=9$ ).

Results: There was no significant difference between the 2 groups regarding demographic and disease characteristics. Statistically significant decrease of blood loss was observed in the vascular control group. Blood loss in group A was nearly a quarter of that in group B.

Conclusion: Temporary intraoperative clamping of the ECA minimizes blood loss, and consequently, the need for blood transfusion with all its complications. In addition, it ensures more optimum survival of the full-thickness graft used for coverage of the head neck defect left after surgery.
\end{abstract}

\section{Introduction:}

Head and neck cancer represents $5 \%$ of all malignant tumors in US and $17 \%$ in Egypt. ${ }^{1}$ The majority of patients present with locally advanced lesions necessitating major surgical excisions and challenging reconstruction. Major hemorrhage during surgery for advanced head and neck tumors is life threatening problem. The control of bleeding through the ligation of the offending artery was clearly the treatment of choice. ${ }^{2}$

Identifying the offending vessel and gaining adequate access to it are often difficult to perform although temporary arrest of the bleeding is usually possible with packing and pressure. Definitive control of the bleeding has historically been achieved with either ligation of the external carotid artery (ECA) or selective embolization. ${ }^{2}$

Ligation of several branches of the ECA reduces collateral blood flow and hence contributes significantly to the arrest of bleeding. Selective embolization of bleeding vessels requires catheterization of the femoral artery, angiography to identify the bleeding vessel and deposition of a thrombogenic agent. Embolization may not be possible if the bleeding vessel is excessively tortuous, small or in vasospasm. Embolization needs a skilled interventional radiologist, professional in angiography and embolization. ${ }^{2}$

Complications of blood transfusion as hemolytic reactions, febrile and allergic reactions, bacterial sepsis, embolism, overtransfusion and pulmonary edema and transmission of diseases (malaria, Chagas' disease, brucellosis and transmission of hepatitis $\mathrm{C}$ and HIV-1) have been dramatically minimized by the introduction of better antibody and nucleic acid screening for these pathogens. ${ }^{3}$ 
The external carotid artery begins at the bifurcation of the common carotid artery at C4. It continues upward to a point posterior to the neck of the mandible (approximately 1.5 $\mathrm{cm}$ below the zygomatic arch) where it bifurcates to form the maxillary and superficial temporal arteries. The superior thyroid, lingual, and facial arteries arise from the ventral aspect near the origin of the external carotid; the ascending pharyngeal, occipital and posterior auricular branches arise from the dorsal side of the external carotid. ${ }^{4}$ The common carotid may bifurcate high at the level of the hyoid bone, or lower at the level of the cricoid cartilage. ${ }^{5}$ External carotid artery also delivers blood to the internal carotid (by virtue of the anastomoses of the two). But, even if there is no vascular disease, it is sufficient in only $50 \%$ of the cases. ${ }^{6}$

The normal relationship of external to internal carotid artery may be altered; the terminology of these vessels in no way represents their relationship in the neck but simply refers to their ultimate distribution. Except for rare circumstances, the internal carotid artery has no branches in the neck, whereas the external carotid artery has three or four branches within several centimeters of the bifurcation. It is best to expose both internal and external carotid arteries for at least $2.5 \mathrm{~cm}$ and ascertain the presence or absence of branches. Avoid injury to the superior laryngeal nerve, which passes deep to external carotid artery. $^{7}$

In this study, we introduce the results of a simple vascular control procedure to minimize intraoperative blood loss, and avoid blood transfusion during resection of advanced head and neck tumors without the need for embolization or ligation of the external carotid artery through vascular clamping to the external carotid artery.

\section{Patients and methods:}

This prospective study was performed in Surgical Oncology Department, Faculty of Medicine, Menofia University and Oral and Maxilliofacial Surgery Department, Faculty of Oral and Dental Medicine, Cairo University between May 2006 and March 2010.

Following thorough clinical examination and routine preoperative laboratory tests, a search of locoregional and distant metastases were done with computed tomography (CT) scan, magnetic resonance imaging (MRI), bone scan and abdominal ultrasonography. Operable head and neck tumors were included and randomized into two groups:

Group A Table(1) includes 11 patients receiving vascular controls to the external carotid artery during neck dissection by vascular clamp before resection of the tumors. Diagnosis of these patients was recurrent mucoepidermoid carcinoma of the parotid $(\mathrm{n}=1)$, sqauamous cell carcinoma of maxillary alveolar margins $(n=2)$, retromolar trigone $(\mathrm{n}=2)$, mandibular alveolar margins $(\mathrm{n}=3)$ and buccal mucosa $(\mathrm{n}=3)$.

Group B Table(2) includes 9 patients who received classical neck dissection and resection of the tumors without vascular control. They suffered squamous cell carcinoma of retromolar trigone $(\mathrm{n}=2)$, mandibular alveolar margin $(\mathrm{n}=5)$ and buccal mucosa $(\mathrm{n}=2)$. 
Table (1): Detailed data of Group (A).

\begin{tabular}{|c|c|c|c|c|c|c|c|}
\hline Serial & $\begin{array}{l}\text { Pathology } \\
\text { + Grade }\end{array}$ & Age & Sex & Site & TNM & Procedure & Blood loss \\
\hline 1 & $\begin{array}{c}\text { Mucoepidermoid } \\
\text { Carcinoma grade } 2\end{array}$ & 58 & male & $\begin{array}{l}\text { Parotid region \& } \\
\text { Buccal mucosa }\end{array}$ & $\begin{array}{c}\text { T4 invade } \\
\text { mandible } \mathrm{N}+\mathrm{ve}\end{array}$ & $\begin{array}{c}\text { Hemimand }+ \text { full thickness skin, } \\
\text { buccal mucosa }+ \text { buccal fat pad }+ \\
\text { Parotidectomy + RND + } \\
\text { Reconstruction PMMF }\end{array}$ & $300 \mathrm{cc}$ \\
\hline 2 & SCC grade 2 & 53 & male & Upper alveolar margin & T2 N0 & $\begin{array}{l}\text { Hemimaxillectomy+ } \\
\text { supraomohyoid ND }\end{array}$ & $100 \mathrm{cc}$ \\
\hline 3 & SCC grade 2 & 46 & female & Upper alveolar margin & T2N0 & $\begin{array}{l}\text { Hemimaxillectomy+ } \\
\text { supraomohyoid ND }\end{array}$ & $90 \mathrm{cc}$ \\
\hline 4 & SCC grade 1 & 65 & male & Right Retromolar trigone & $\mathrm{T} 2 \mathrm{~N} 0$ & $\begin{array}{c}\text { Excision + Right } \\
\text { Hemimandibulectomy + FND }\end{array}$ & $200 \mathrm{cc}$ \\
\hline 5 & SCC grade 2 & 46 & male & Right Retromolar trigone & $\mathrm{T} 2 \mathrm{~N} 0$ & Hemimandibulectomy. +FND & $200 \mathrm{cc}$ \\
\hline 6 & SCC grade 1 & 68 & female & Left Lower alveolar margin & $\mathrm{T} 2 \mathrm{~N} 0$ & $\begin{array}{c}\text { Excision + Left } \\
\text { hemimandibulectomy + FND }\end{array}$ & $180 \mathrm{cc}$ \\
\hline 7 & SCC grade 2 & 59 & male & Left Lower alveolar margin & $\mathrm{T} 2 \mathrm{~N} 0$ & $\begin{array}{c}\text { Excision + Left } \\
\text { hemimandibulectomy + FND }\end{array}$ & $170 \mathrm{cc}$ \\
\hline 8 & SCC grade 2 & 68 & male & Left Lower alveolar margin & T3 N +ve & Left hemimandibulectomy $+\mathrm{FND}$ & $200 \mathrm{cc}$ \\
\hline 9 & SCC grade 1 & 57 & female & Right Buccal mucosa & T1 N0 & Right bExcision+FND & $100 \mathrm{cc}$ \\
\hline 10 & SCC grade 3 & 51 & male & Right Buccal mucosa & T2 N0 & $\begin{array}{c}\text { Excision with skin+ RND + } \\
\text { reconstruction PMMF }\end{array}$ & $250 \mathrm{cc}$ \\
\hline 11 & SCC grade 3 & 45 & male & Left Buccal mucosa & T4 N+ve & $\begin{array}{l}\text { Full thickness resection + } \\
\text { hemimandbulectomy +RND + } \\
\text { reconst. PMCF(Double island) }\end{array}$ & $270 \mathrm{cc}$ \\
\hline
\end{tabular}

Table (2): Detailed data of Group (B).

\begin{tabular}{|c|c|c|c|c|c|c|c|}
\hline Serial & $\begin{array}{c}\text { Pathology } \\
\text { + Grade }\end{array}$ & Age & Sex & Site & TNM & Procedure & Blood loss \\
\hline 1 & SCC grade 2 & 59 & female & Retromolar trigone & T2N0 & $\begin{array}{c}\text { Excision+ } \\
\text { Hemimandibulectomy +FND }\end{array}$ & $900 \mathrm{cc}$ \\
\hline 2 & SCC grade 2 & 45 & male & Retromolar trigone & T2N0 & $\begin{array}{c}\text { Excision + } \\
\text { Hemimandibulectomy +FND }\end{array}$ & $850 \mathrm{cc}$ \\
\hline 3 & SCC grade 3 & 59 & Female & Left Lower Alveolar margin & T3 N0 & $\begin{array}{c}\text { Left Hemimandbulectomy } \\
+ \text { FND }\end{array}$ & $700 \mathrm{cc}$ \\
\hline 4 & Scc grade 2 & 60 & male & Left Lower alveolar margin & T2 N0 & $\begin{array}{c}\text { Left hemimandibulectomy } \\
+ \text { FND }\end{array}$ & $700 \mathrm{cc}$ \\
\hline 5 & SCC grade 4 & 45 & female & right Lower alveolar margin & T4 N +ve & $\begin{array}{c}\text { Lower alveolar margin Right. } \\
+ \text { Floor of mouth } \\
\text { + Right hemithyroidectomy + } \\
\text { RND+ PMMF }\end{array}$ & $950 \mathrm{cc}$ \\
\hline 6 & SCC grade 2 & 53 & male & Left Lower alveolar margin & T2 N +ve & Left hemimandibulectomy +FND & $600 \mathrm{cc}$ \\
\hline 7 & SCC grade 2 & 56 & male & right Lower alveolar margin & T2 N0 & $\begin{array}{c}\text { Right Hemimandibulectomy } \\
\text { FND }\end{array}$ & $600 \mathrm{cc}$ \\
\hline 8 & SCC grade 2 & 45 & male & Left Buccal mucosa & T2 N0 & $\begin{array}{c}\text { CompositeExcision+Skin } \\
+ \text { RND + PMMF }\end{array}$ & $\begin{array}{c}900 \mathrm{cc} \\
\text { +RND+ PMMF }\end{array}$ \\
\hline
\end{tabular}

$S C C=$ Squamous cell carcinoma, $F N D=$ Functional neck dissection, $R N D=$ Radical neck dissection, $P M M F=$ Pectoralis major myocutaneous flap. 
In Group A during neck dissection after upper and lower flap elevation including the platysma muscle, an incision was made along the anterior border of the sternocleidomastoid muscle exposing the carotid sheath. The internal jugular vein with the ansa hypoglossi was retracted laterally. The common facial vein may require ligation and transection. The bifurcation of the common carotid artery was thus exposed, with the external carotid artery in a more anterior plane and the internal carotid artery in a more posterior plane. The internal carotid has no branches in the neck-there are very rare exceptions to this rule of thumbwhereas the external carotid does have branches. The first branch is the ascending pharyngeal, which is in the inner aspect of the bifurcation, is rather small, and is hidden by the network of the carotid sinus. The second branch, which is the one most readily seen and identified, is the superior thyroid artery. This branch is on the anteromedial aspect of the external carotid and serves as the identifying landmark. The next branch lying in the region of the anterior belly of the digastricus is either the lingual or external maxillary artery (facial artery). The external carotid was carefully dissected from the enveloping fascia and nerves of the carotid sinus.

Temporary vascular occlusion of the external carotid artery above the level of the superior thyroid artery was done by vascular clamp and complete neck dissection enblock with total resection of the primary tumor. During the resection and neck dissection the estimated blood loss was measured by weighing the surgical gauzes before and after soaking by patient blood during the procedure.

\section{Statistical analysis:}

Data was analyzed using SPSSwin statistical package version 15 (SPSS Inc., Chicago, IL). Numerical data were expressed as mean and standard deviation. Qualitative data were expressed as frequency and percentage. Fisher's exact test was used to examine the difference between the two groups in qualitative variables. For quantitative data, comparison between two groups was done using MannWhitney test. A p-value $<0.05$ was considered significant.

\section{Results:}

Table(3) summarizes the results of this study. There was no significant difference between group A and group B regarding demographic and disease characteristics. Statistically significant decrease of blood loss was observed in group A (vascular control group). Blood loss in group A was nearly a quarter of that in group B (without vascular control).

All cases showed uneventful postoperative healing except three cases. In group B, case no. 8 there was wound infection and dehiscence one week postoperatively. Antibiotic administration, surgical debridement and resuturing of the gapped areas showed normal healing. In the same group, case no. 9 showed small salivary fistula which was managed conservatively by Ryle feeding and antibiotic administration. While in group A, case no. 11, partial loss of the skin of PMMF was observed 5 days postoperative and managed by surgical debridement and frequent dressing. 
Table (3): Demographic and disease characteristics and intraoperative blood loss of the two studied groups.

\begin{tabular}{|c|c|c|c|}
\hline & $\begin{array}{c}\text { Group A } \\
\mathrm{n}=11\end{array}$ & $\begin{array}{c}\text { Group B } \\
\mathrm{n}=9\end{array}$ & P value \\
\hline Age & $56.0 \pm 8.6$ & $52.2 \pm 6.5$ & 0.370 \\
\hline Sex (male/female) & $8 / 3$ & $6 / 3$ & 0.769 \\
\hline Site & & & \\
\hline Buccal mucosa & $3(27.3 \%)$ & $2(22.2 \%)$ & \\
\hline Lower Alveolar margin & $3(27.3 \%)$ & $5(55.6 \%)$ & \\
\hline Retromolar trigone & $2(18.2 \%)$ & $2(22.2 \%)$ & \\
\hline Upper alveolar margin & $2(18.2 \%)$ & $0(0.0 \%)$ & \\
\hline Parotid region & $1(9.1 \%)$ & $0(0.0 \%)$ & \\
\hline T stage & & & 0.670 \\
\hline Stage 1 \& 2 & $6(54.5 \%)$ & $6(66.7 \%)$ & \\
\hline Stage 3 \& 4 & $5(45.5 \%)$ & $3(33.3 \%)$ & \\
\hline N stage & & & \\
\hline N0 & $8(72.7 \%)$ & $6(66.7 \%)$ & 1.000 \\
\hline N1 & $3(27.3 \%)$ & $3(33.3 \%)$ & \\
\hline Differentiation grade & & & 1.000 \\
\hline Grade 1 \& 2 & $9(81.8 \%)$ & $7(77.8 \%)$ & \\
\hline Grade 3 \& 4 & $2(18.2 \%)$ & $2(22.2 \%)$ & \\
\hline Intraoperative Blood Loss & $187.3 \pm 70.0$ & $783.3 \pm 134.6$ & \\
\hline
\end{tabular}




\section{Case (1)}

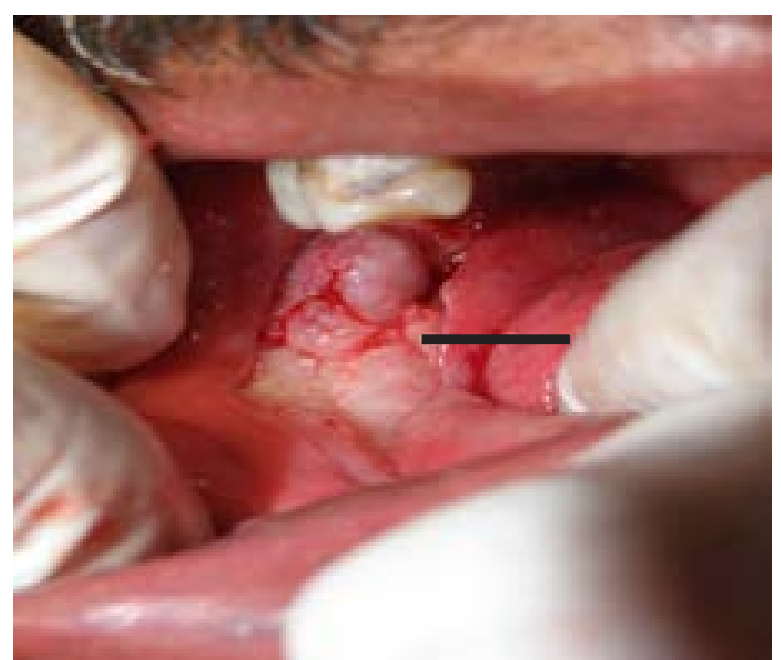

Figure (1A): Clinical presentation of SCC at alveolar margin region.

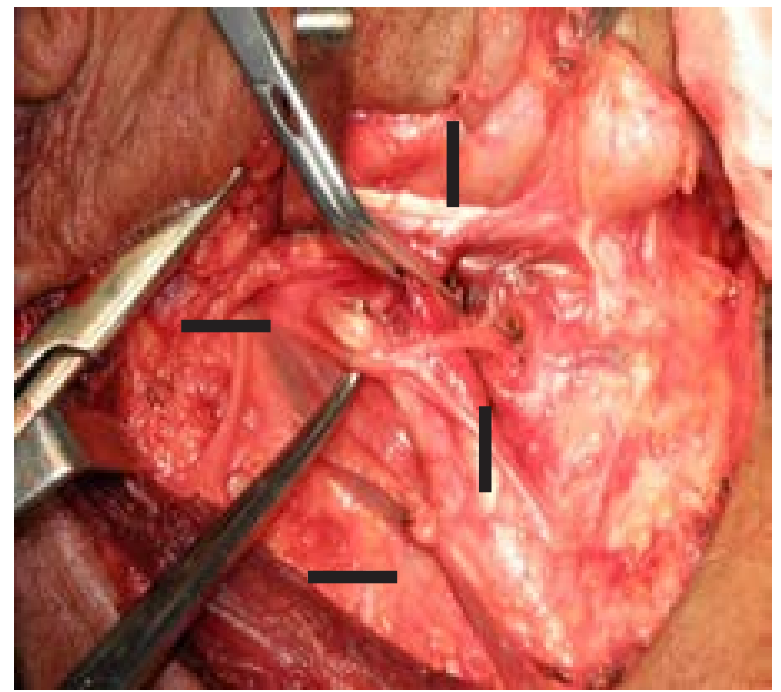

Figure (1C): arrows showing vascular control of external carotid artery, internal carotid artery, hypoglossal nerve \& descendens hypoglossi crossing over the carotid vessels, common carotid artery.

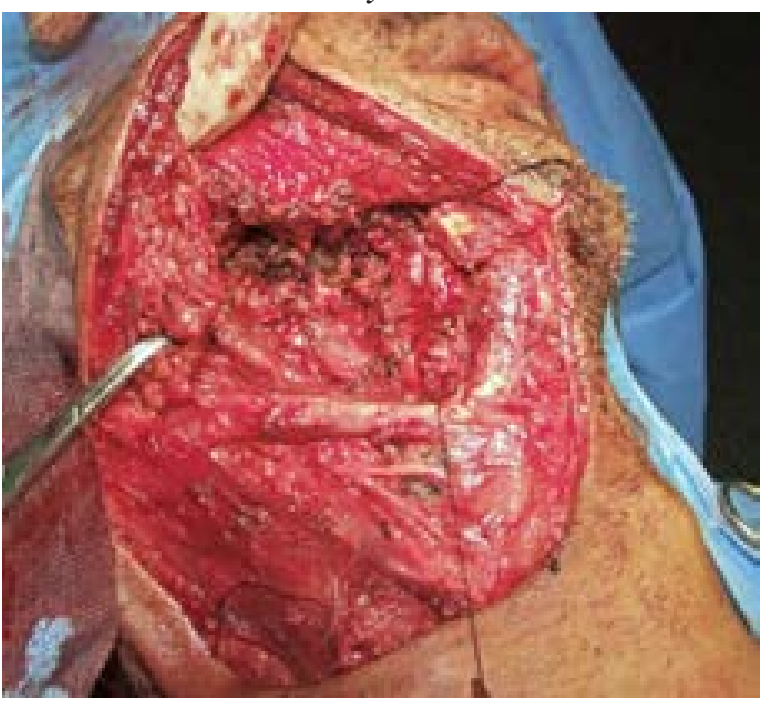

Figure (1E): After complete resection and neck dissection.

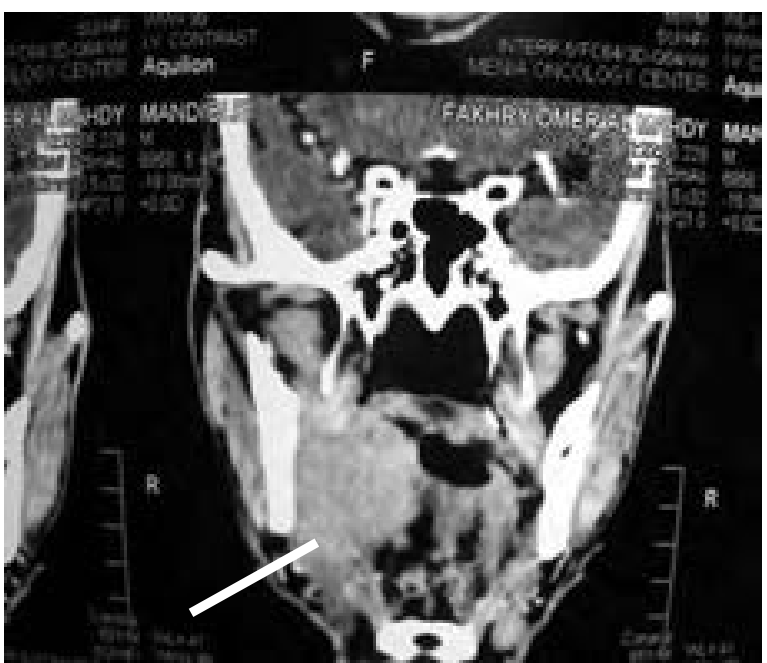

Figure (1B): Coronal C.T. section showing tumor and the extension to the parapharyngeal space.

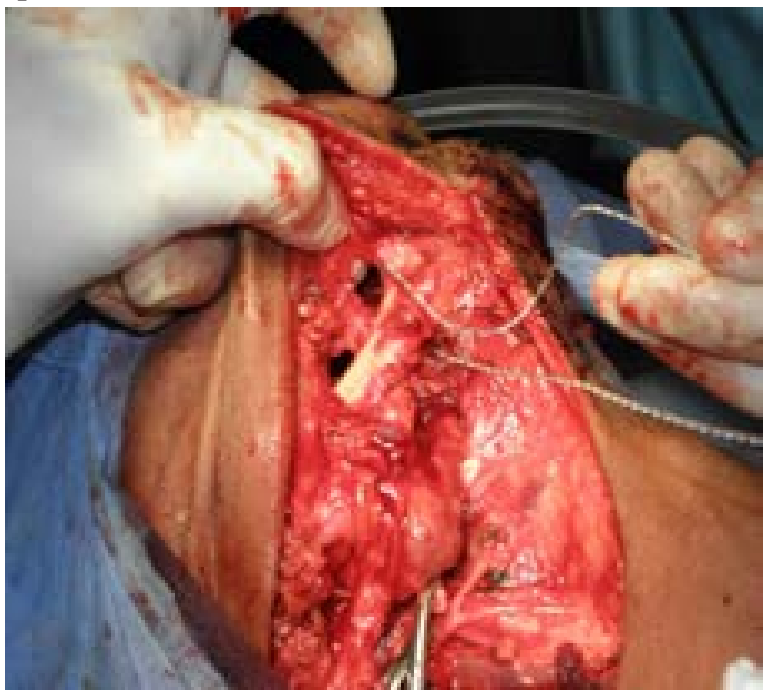

Figure (1D): Anterior osteotomy cut starting the hemimandibulectomy.

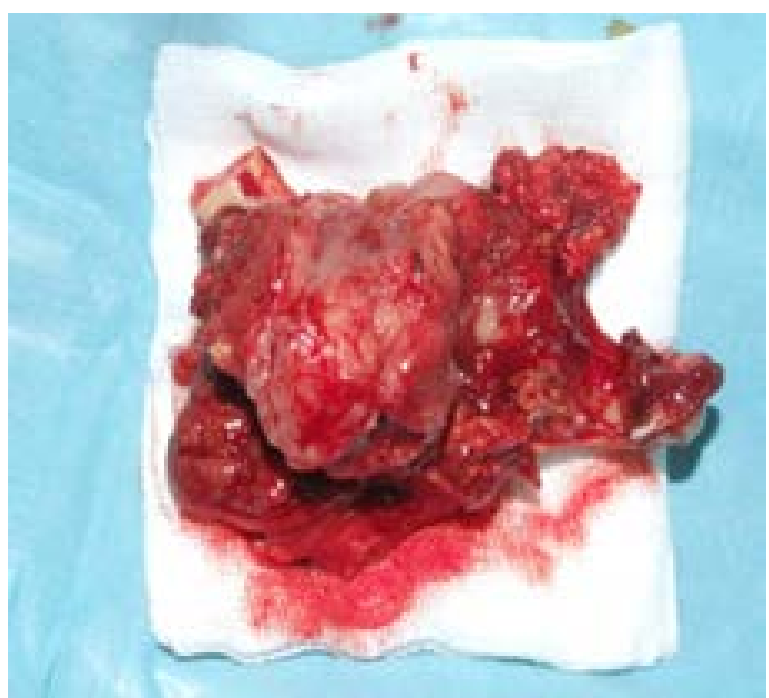

Figure ( $1 F)$ : The specimen. 


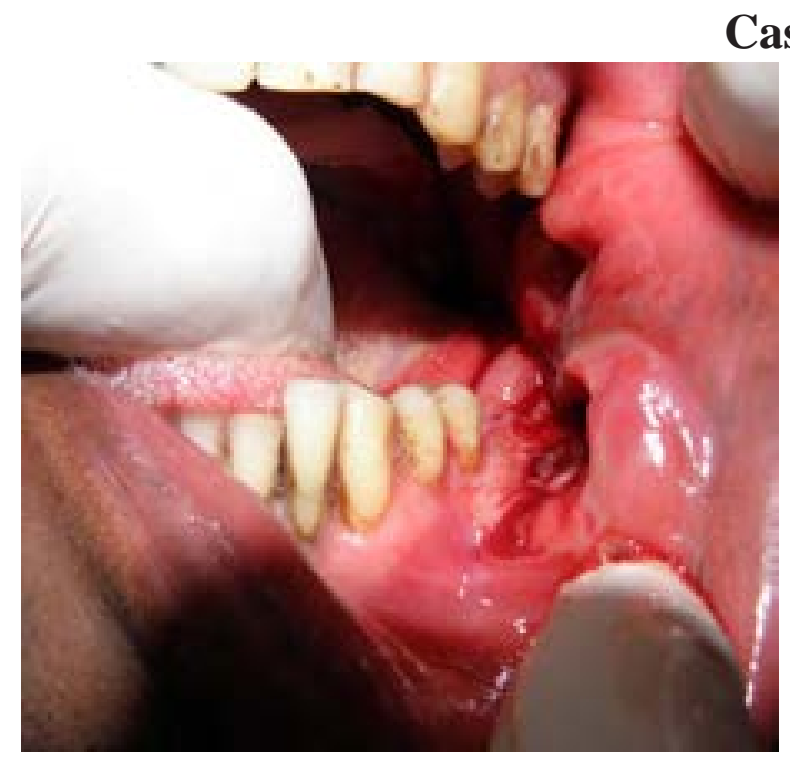

Figure (2A): Clinical presentation of SCC at buccal mucosa.

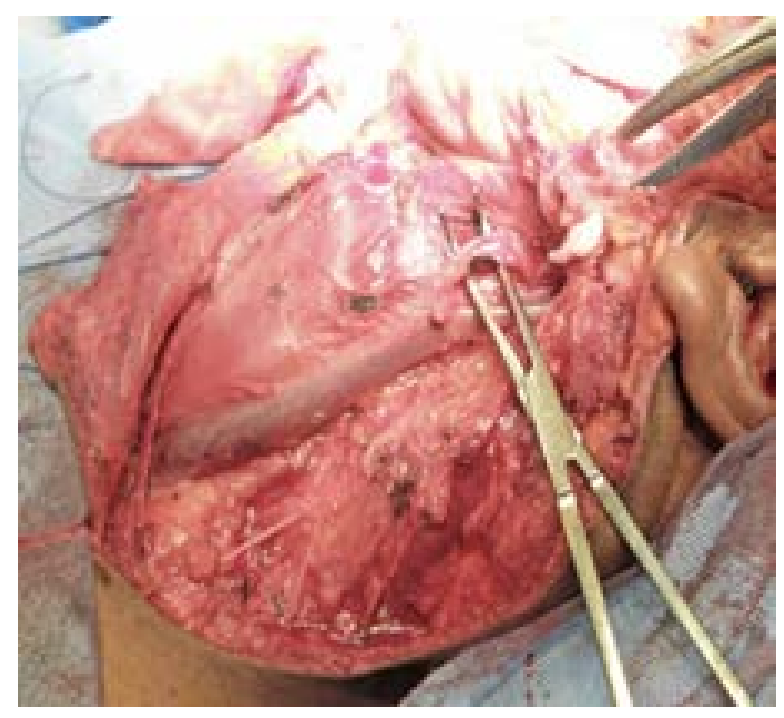

Figure (2C): Identification of external carotid.

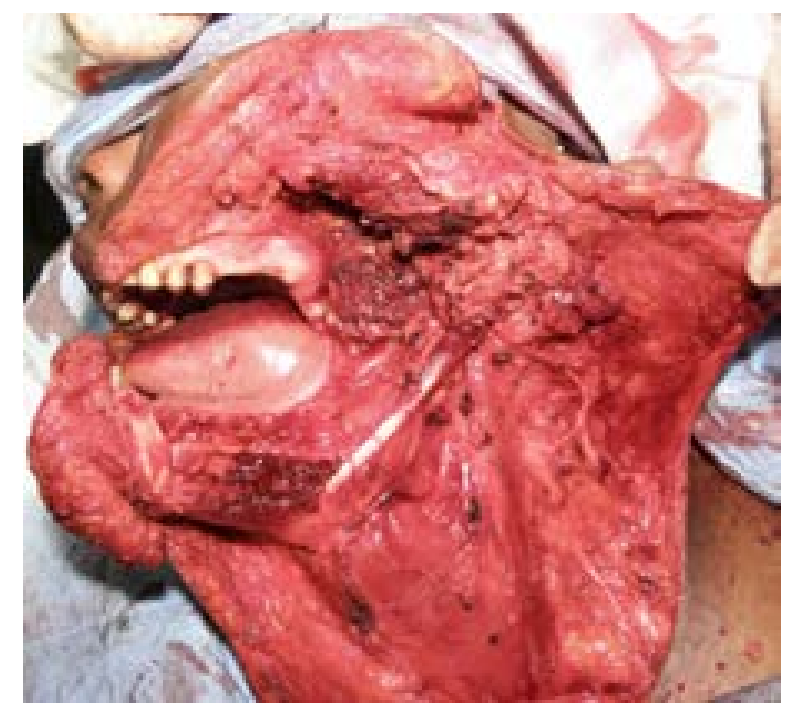

Figure (2E): Completed resection and neck dissection, notice the clean and dry field after resection.

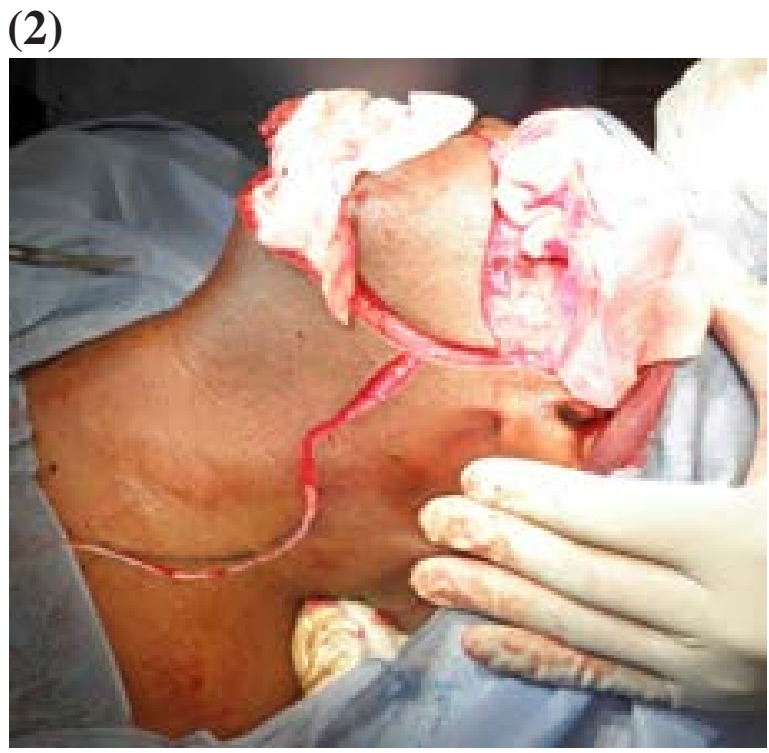

Figure (2B): Incision design to include the overlying skin and incision for neck dissection.

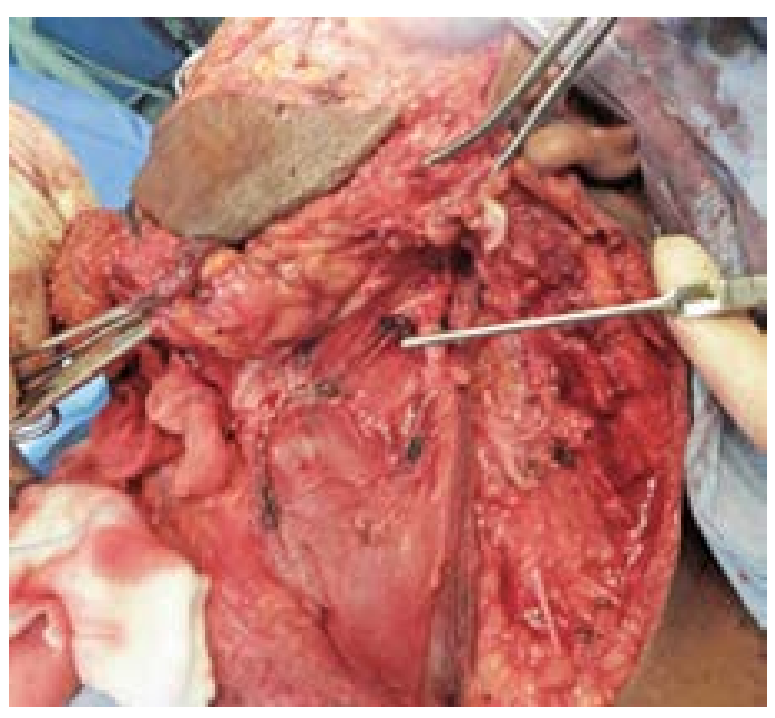

Figure (2D): Vascular control of external carotid artery before resection.

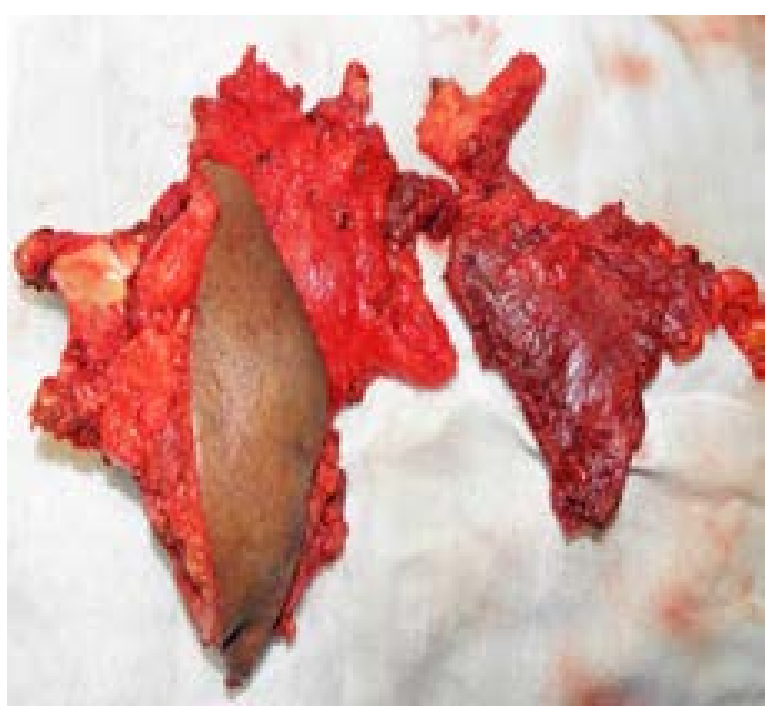

Figure $(2 F)$ : The specimen. 


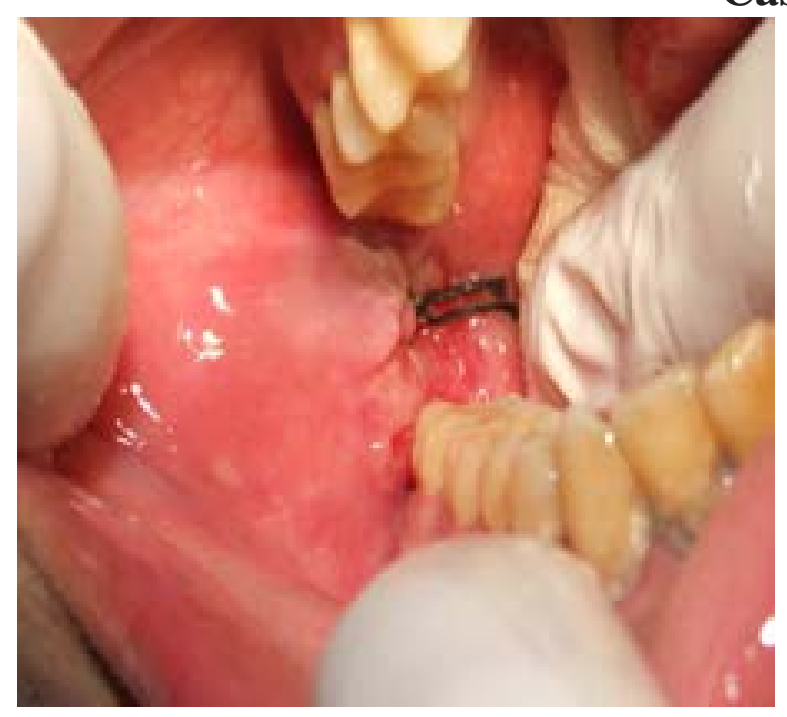

Figure (3A): Clinical presentation of SCC at retromolar trigon.

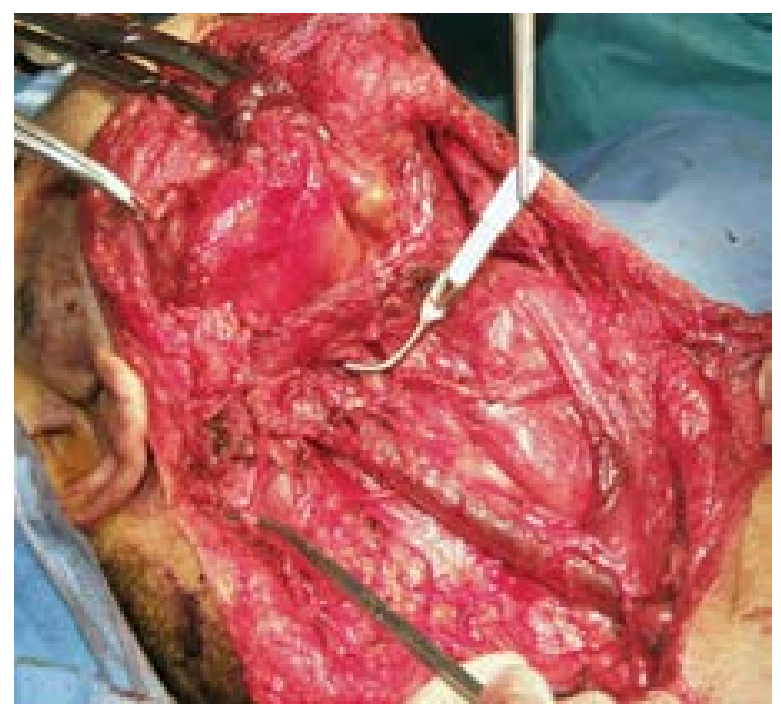

Figure (3C): Vascular control of the external carotid artery by vascular clamp before complete resection.

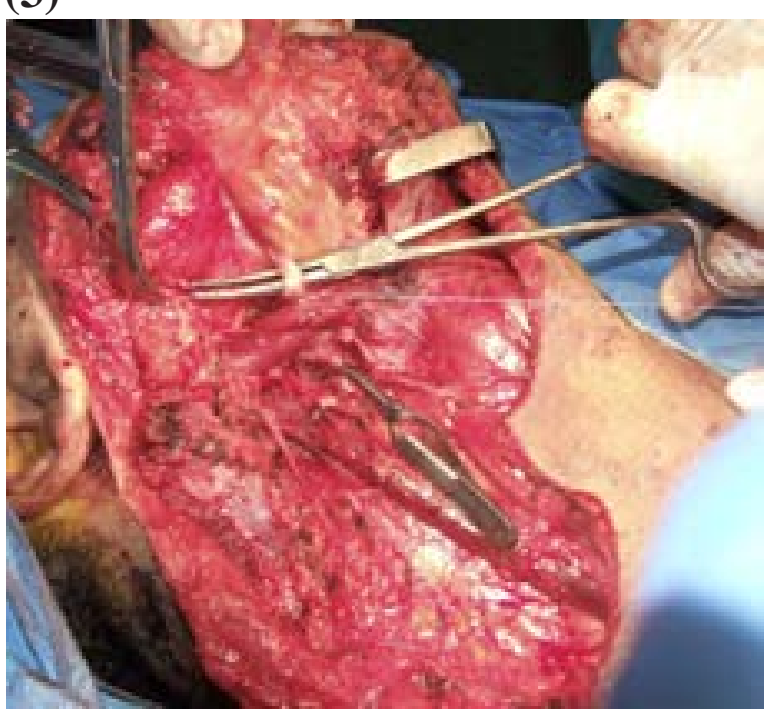

Figure (3B): Identification of the facial artery.

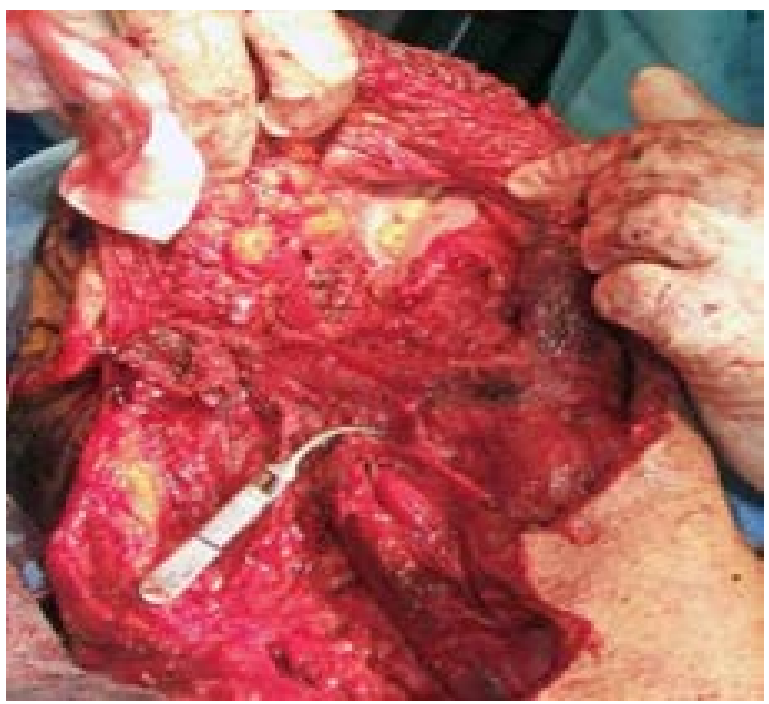

Figure (3D): After complete resection and neck dissection, notice the vascular clamp to ECA and the dry clean field.

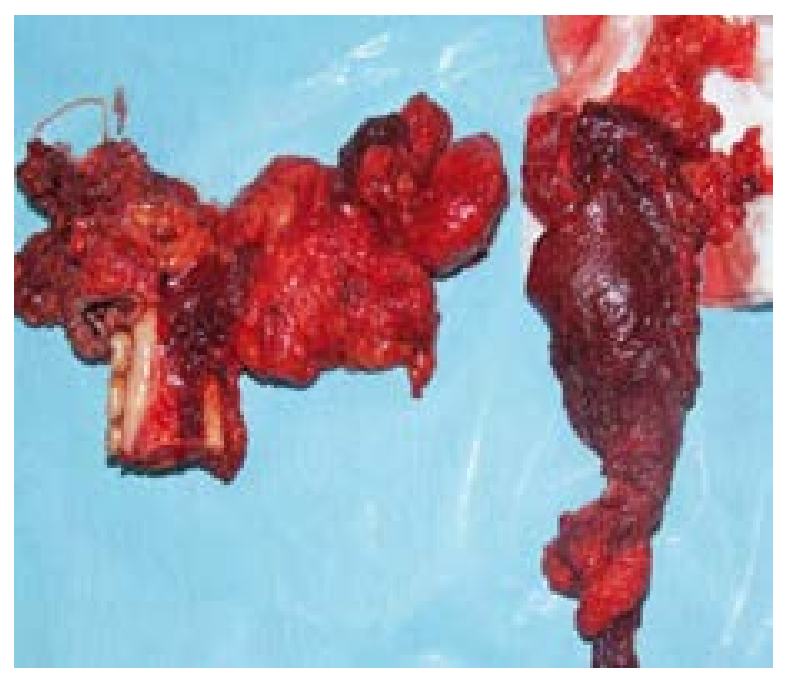

Figure (3E): The specimen. 

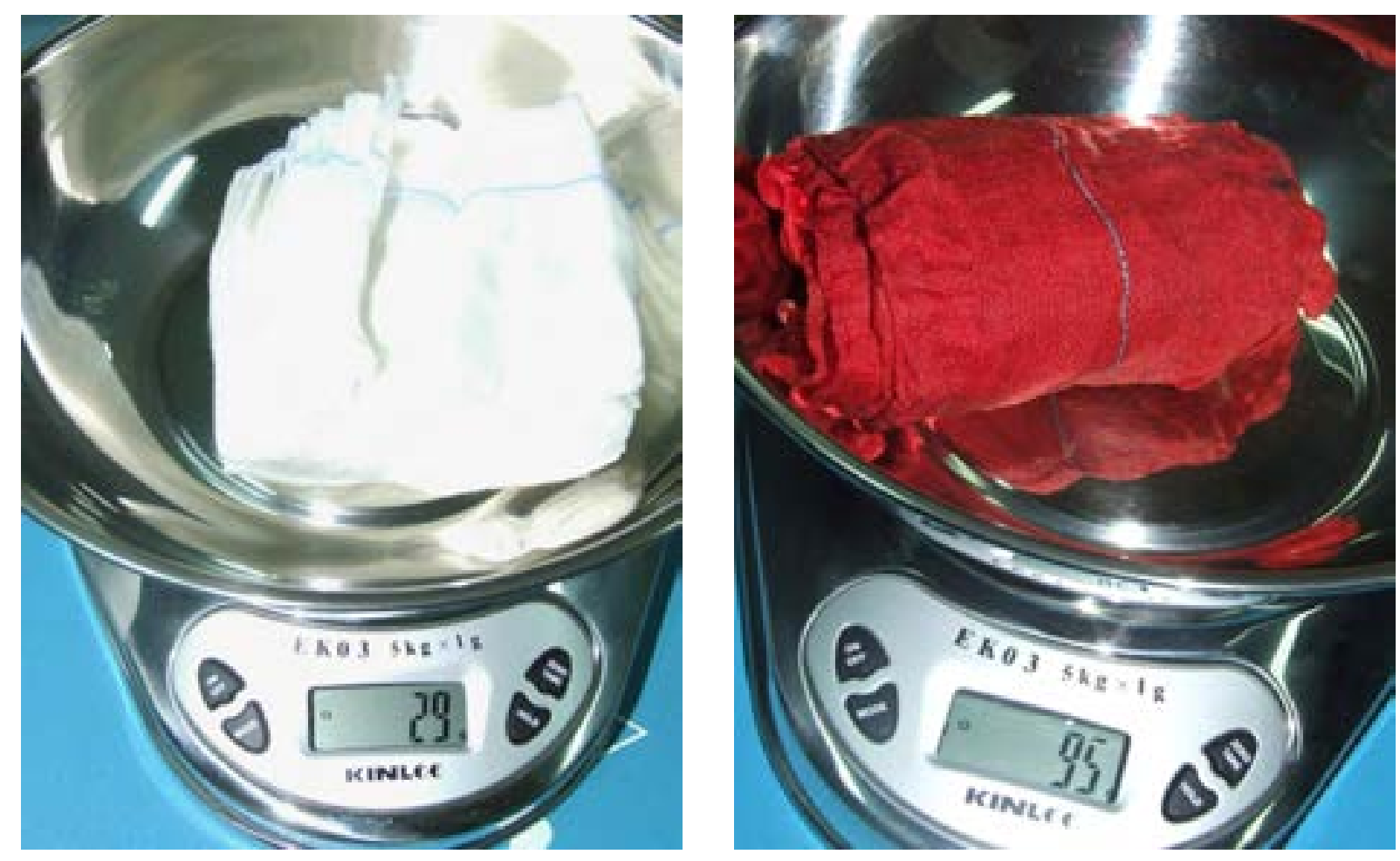

Figure (4): Weighing of the gauze before and after blood soacking.

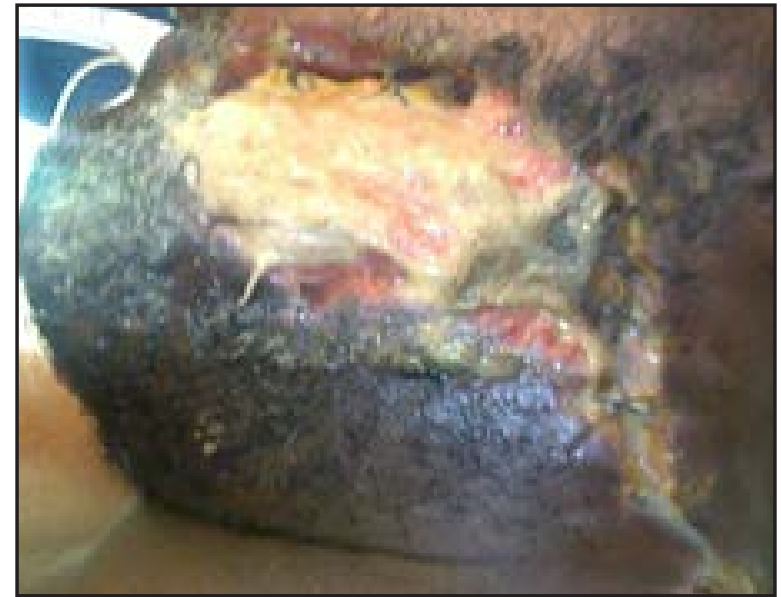

Figure (5A): Clinical presentation of infection and dehiscence.

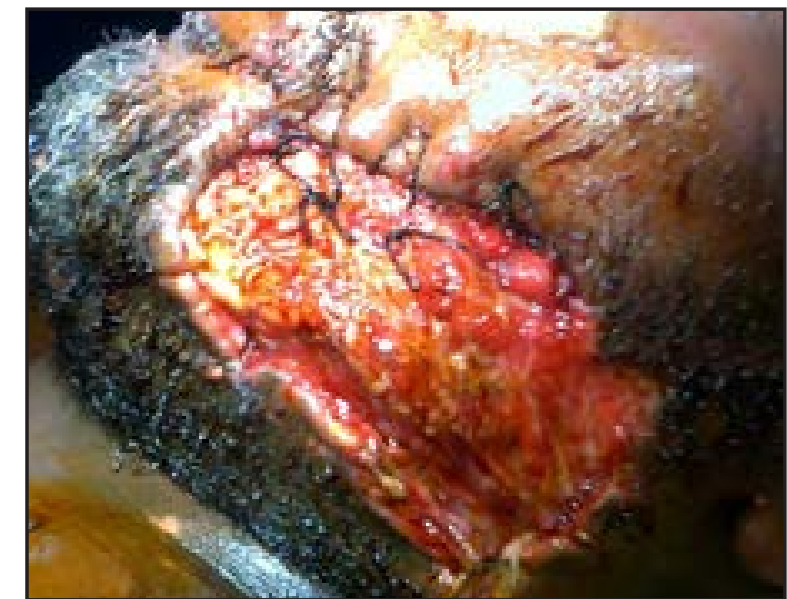

Figure (5B): Postoperative surgical debridement.

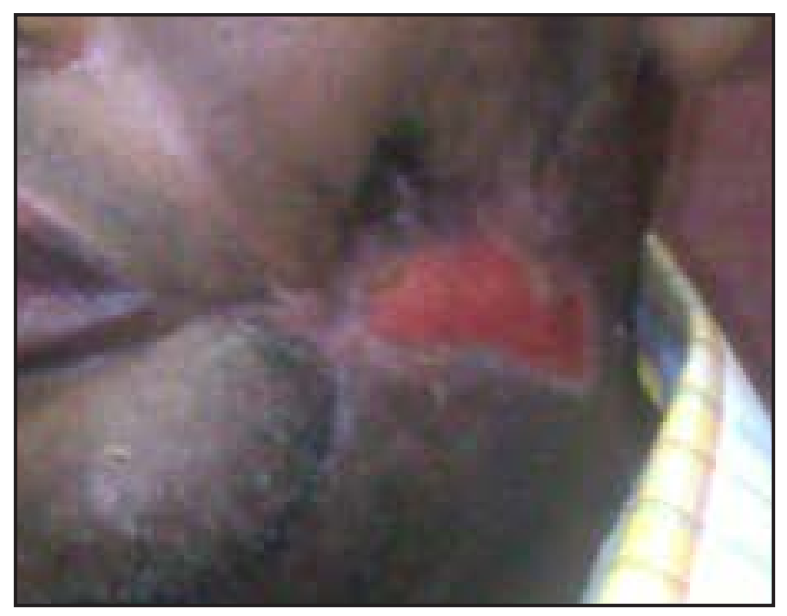

Figure (5C): Normal partial wound healing one month postoperative. 


\section{Discussion:}

Patients with advanced head and neck malignancies are prone to many problems, including bleeding, infection, fistula, and uncontrollable pain. Massive hemorrhage is the most serious and immediate of these complications. Bleeding from an unresectable or advanced local recurrent malignancies of the head and neck, which can occur either from the tumor bed or from erosion into a large vessel, represents a difficult management problem. 8 Past management of tumor hemorrhage has included ligation of the carotid artery and transarterial embolization using polyvinyl alcohol (PVA) and a detachable balloon. ${ }^{8-12}$

Ligation of the external carotid artery (ECA) is a relatively simple procedure with minimal morbidity, however, its efficacy in arresting ongoing blood loss is questionable. It was reported to be successful in 2 of 3 cases of hemorrhage after Le Fort osteotomy, 13 in 4 of 5 patients having hemorrhage during mandibular osteotomies ${ }^{14}$ and in bleeding after temporo-mandibular joint surgery. ${ }^{15}$

In this study, we question the necessity of ligation of ECA to minimize intraoperative blood loss during resection of advanced head and neck tumors. Ligation is a permanent procedure that is undesirable in these cases. We need a temporary procedure for intraoperative vascular control to allow good operative field during surgery and well perfused bed which in turn ascertains a better healing during the postoperative period. Using temporary intraoperative clamping of the ECA, we found a statistically significant decrease of blood loss mounting to nearly a quarter of blood loss in patients where carotid arteries were left unclamped.

In the control group with unclamped ECA, the estimated blood loss reached nearly 1 liter. The management of oral and oropharyngeal cancer involves prolonged surgical procedures for tumour resection and flap reconstruction which result in significant intraoperative blood loss. The reported transfusion rates varied from $32 \%$ to $81 \% .16$ Vamvakas \& Blajchman ${ }^{17}$ suggest that transfusion of 3 or more units of blood is associated with a worse outcome in oropharyngeal cancer patients, with a reduction in survival and an increase in recurrence rates.
Other investigators reported an almost fivefold increase in the risk of death among patients transfused more than 3 units of blood compared to nontransfused patients. ${ }^{16,18}$

Thus, clamping of ECA to minimize blood loss and hence blood transfusion may have an impact on both short- and long term treatment outcome in advanced head and neck malignancies. This needs to be proved in longer follow-up studies.

Our protocol of management of head and neck malignancies involved covering large defects with locoregional flaps such as pectoralis major myocutaneous falp. Vascularity of the grafted bed has a considerable role in graft healing. In a study evaluating the use of full-thickness skin grafts following excision of precancerous and cancerous oral lesions, the authors concluded that the scarcity of the blood supply in the grafted bed, and the uneven pressure and immobilization of the grafted skin, influence the success of the procedure. 19

Insufficient recipient bed vascularity is a well known cause of graft failure in addition to hematoma, seroma, infection, excessive tension, mechanical shearing forces, and improper postoperative care. This tends to affect full thickness skin grafts, which have a greater surface area to nourish and support, more than split thickness skin grafts. ${ }^{20}$

These effects occur early in the ischemic period. Even after that factors that decrease the blood supply nourishing the graft as cigarette smoking and diabetes mellitus, may pose more complications to the grafted site. 21-23

We believe that permanent ligation of the external carotid artery as well as arterial emobolization may add to these factors causing graft failure. Consequently, temporary clamping of ECA seems a better way to optimize graft survival.

\section{Conclusion:}

In summary, temporary intraoperative clamping of the ECA minimizes blood loss, and need for blood transfusion with all its complications. In addition, it ensures more optimum survival of the full-thickness graft used for coverage of the head neck defect left after surgery. 


\section{References:}

1- El-Bolkainy N: Head and neck cancer. In: Topographic pathology of cancer NCI, 2000; Cairo University.

2- Bouloux GF and Perciaccante VJ: Massive hemorrhage during oral and maxillofacial surgery: Ligation of the external carotid artery or embolization. J Oral Maxillofac Surg 2009; 67: 1547-1551.

3- Schwartz: Principles of surgery. McGrawHill's, Chp 3; Oct 2007.

4- Skandalakis' Surgical Anatomy. Chap 1; 2004.

5- Wind GG, Valentine RJ: Anatomic exposures in vascular surgery. Baltimore: Williams \& Wilkins (Publishers); 1991.

6- Roberts B, Hardesty WH, Holling HE, Reivich M, Toole JF: Studies on extracranial cerebral blood flow. Surgery 1964; 56: 826.

7- Lore \& Medina: An atlas of head \& neck surgery. $4^{\text {th }}$ edn; 2009; p. 1336.

8- Bhansali S, Wilner H, Jacobs JR: Arterial embolization for control of bleeding in advanced head and neck carcinoma. $J$ Laryngol Otol 1986; 100: 1289-1293.

9- Wilner HI, Lazo A, Metes JJ, Beil KA, Nowack P, Jacobs J: Embolization in cataclysmal hemorrhage caused by Squamous cell carcinomas of the head and neck. Radiology 1987; 163: 759-762.

10-Feifel H, Voile E, Riediger D, GustorfAeckerle R: Superselective embolization in an errosive haemorrhage of a carcinoma in the parotid gland. Int J Oral Maxillofac Surg 1991; 20: 369-370.

11-Morrissey DD, Andersen PE, Nesbit GM, Bamwell SL, Everts EC, Cohen JI: Endovascular management of hemorrhage in patients with head and neck cancer. Arch Otolaryngol Head Neck Surg 1997; 123: 15-19.

12-Kaufinan SL: Simplified method of transcatheter embolization with polyvinyl alcohol foam (Ivalon). AJR 1979; 132: 853.
13-Lanigan DT, West RA: Management of postoperative hemorrhage following Le Fort I maxillary osteotomy. J Oral Maxillofac Surg 1984; 42: 367.

14-Lanigan DT, Hey J, West R: Hemorrhage following mandibular osteotomies: A report of 21 cases. J Oral Maxillofac Surg 1991; 49: 713.

15-Vallerand WP, Dolwick MF: Complications of temporomandibular joint surgery. Oral Maxillofac Surg Clin North Am 1990; 2: 481.

16-Taniguchi Y, Okura M: Prognostic significance of perioperative blood transfusion in oral cavity squamous cell carcinoma. Head Neck 2003; 25: 931-936.

17-Vamvakas EC, Blajchman MA: Deleterious clinical effects of transfusion-associated immunomodulation: Fact or fiction? Blood 2001; 97: 1180-1195

18-Szakmany T, Dodd M, Dempsey GA, et al: The influence of allogenic blood transfusion in patients having free-flap primary surgery for oral and oropharyngeal squamous cell carcinoma. Br J Cancer 2006; 94(5): 647-53.

19-Yoshimura Y, Matsuda S, Obara S. Fullthickness skin grafting of postsurgical oral defects: Short- and long-term outcomes. $J$ Oral Maxillofac Surg 1995; 53(9): 9981003.

20-Ratner D: Skin grafting. Semin Cutan Med Surg 2003; 22(4): 295-305.

21-Goldminz D, Bennett R: Cigarette smoking and flap and full-thickness graft necrosis. Arch Dermatol 1991; 127: 1012-1015.

22-Johnson T, Ratner D, Nelson B: Soft tissue reconstruction with skin grafting. $J \mathrm{Am}$ Acad Dermatol 1992; 27(2 Pt 1): 151-165.

23-Johnson T, Ratner D: Skin Grafts. In: Textbook of Dermatologic Surgery. Ratz JL (Editor); Philadelphia, PA, LippincottRaven (Publisher); 1998; p. 201-221. 